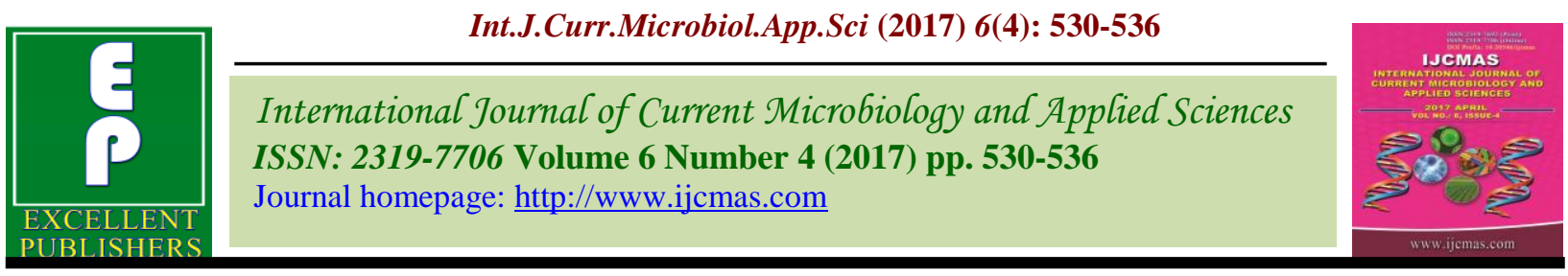

Original Research Article

https://doi.org/10.20546/ijcmas.2017.604.064

\title{
Development of an Automatic Cleaning Mechanism for the Mesh Filter of Roof Water Harvesting
}

\author{
S.V. Lakshminarayana* and K.K. Sathian \\ Kelappaji College of Agricultural Engineering and Technology, Tavanur, \\ Thrissur - 679 573, Kerala, India \\ *Corresponding author
}

\begin{abstract}
A B S T R A C T
Keywords

Rainwater

harvesting, Mesh

filter, Total

suspended solids,

Automatic valve.

Article Info

Accepted:

06 March 2017

Available Online:

10 April 2017

One of the easiest and efficient way of water conservation to solve drinking water scarcity is rooftop water harvesting. However, the technology has some limitations with regard to its purification system. The commonly used sand and gravel filter is very prone to clogging and its cleaning is not an easy job. At the same time, the alternative upward flow mesh filter needs further improvement in cleaning efficiency and some hassle free drain cum back washing mechanism. In upward flow mesh filter system, which creates anaerobic condition will give foul smell. For avoiding anaerobic condition an automatic cleaning mechanism for roof water harvesting has been developed. The automatic cleaning mechanism was giving $92 \%$ removal of the filtered out impurities from the filter system. Further, the automatic flushing unit was draining the upward flow mesh filter unit completely avoiding all possibilities of any anaerobic decomposition. It can be concluded that the automatic flushing unit was a success in improving the performance of the upward flow filter system.
\end{abstract}

\section{Introduction}

The most commonly available filter system for rainwater harvesting consists of sand and gravel media placed in a container. They are usually made of ferrocement casing and are fitted to the top of the storage tank. In Kerala, the most important impurity to be removed from rooftop rain water is the organic impurities such as mosses and other small vegetation. The type of micro mesh filters used in this system has proved to be an alternative to sand and gravel media filter. They also facilitate very ease of periodic cleaning besides having good cleaning efficiency. At the same time, micromesh filters require further modifications and improvisations to make it more efficient and user friendly. One of the major limitations of this filter system is its requirement of very high periodic cleaning (preferably on a daily basis), in order to avoid the foul smell developed due to decomposition of organic impurities in the stagnant water on the inlet side of the micro mesh filter. Hence, an automatic cleaning system for the micro mesh filter system was an immediate necessity. Also, testing of smaller size micro mesh filters were required to evaluate their filtration efficiency and discharge capacity.

Therefore, in this context, this study has been proposed to develop an automatic cleaning mechanism for roof water harvesting and to 
evaluate different sizes of micro mesh filters with the given below specific objectives.

\section{Materials and Methods}

\section{Study area}

Development of an automatic cleaning mechanism for roof water harvesting system and its evaluation have been conducted on the various micro mesh filter in the campus of Kelappaji College of Agricultural Engineering and Technology (KCAET), Tavanur, Malappuram Dt, Kerala, India. The Geographical reference of the study area is $10^{\circ} 51^{\prime} 20^{\prime \prime} \mathrm{N}$ latitude and $75^{\circ}$ 59' $5 " \mathrm{E}$ longitude.

\section{Development of upward flow micro mesh filter system}

The study includes the development of $60 \mu$, $40 \mu, 25 \mu, 15 \mu, 12 \mu, 7 \mu, 5 \mu$ and $3 \mu$ mesh filters. In all the cases, the micro meshes used were made of stainless steel of grade 316 . To make the filter element, $50 \mathrm{~mm}$ PVC pipe of $30 \mathrm{~cm}$ length is taken and slots of $5 \mathrm{~mm} \phi$ were made on it at an approximate spacing of $15 \mathrm{~mm}$ centre to centre in the case of all filters except for 40 micron mesh filter.

Number of holes in these filters varies from 196 to 230. Mesh area and slot area of different filter elements are shown in table 1.

The filter elements were fitted in a casing pipe of $90 \mathrm{~mm} \phi$ PVC. With the help of threaded end cap, the unit is made easily detachable to the filter assembly. Developed Automatic cleaning mechanism for upward flow micro mesh filter system is provided at the bottom of the filter unit. The automatic cleaning mechanism developed for upward flow micro mesh filter system is shown in figure 1 .

\section{Development of automatic flushing system}

Automatic flush system consists of a solenoid valve of $50 \mathrm{~mm} \phi$ (1.5 inch $\phi)$ which is connected to the bottom of the micro mesh filter. The solenoid valve is made to open once a day automatically for about 10 seconds in order to flush out the impurities collected at the bottom of the micro mesh filter. When the solenoid valve opens, all the water collected in the casing pipe and the conveyance pipe fitted above the filter will be flowed down with high velocity. In this gush of water, all the impurities present in the filter unit will get flushed out and the filter will be clean and will be free of all the organic impurities.

Automatic operation of the solenoid valve is achieved through a light sensing- mechanism. When the valve is opened once, it remains open for 10 seconds so that there is enough opportunity for the impurities to get flushed out. Valve again will be opened after every first light incidence on the sensor after a dark period. The valve is connected to a 24 volts electric supply the circuit diagram of the valve unit is given in figure 2 .

\section{Estimation of water quality parameters}

A water quality analyzer, Systronics Water Quality Analyser 371 was used to carry out the physical analysis of the collected rooftop rain water samples. It is a micro controller based instrument for measuring $\mathrm{pH}$, salinity, electrical conductivity and TDS in water sample one at a time. The analyser provides both automatic and manual temperature compensation. Calibration or standardization of the instrument was done with standard solutions. Provision for storing calibration of all appropriate modes is provided with the help of battery backup. This data can be further used for measuring the unknown, without recalibrating the instrument even after switching it off. A $20 \times 2$ alphanumeric LCD 
display along with 14 keys enables the user to select, set and operate the unit with ease. All the results will be displayed electronically on the display unit.

The important physical parameters which include $\mathrm{pH}$, electrical conductivity, salinity and TDS of the rainwater and roof water samples collected for the study were tested with water quality analyser.

\section{Total suspended solids by gravimetric method}

Total suspended solids (TSS) are defined as the portion of total solids in a water sample retained by a glass fiber filter of pore size greater than $2 \mu$. Total suspended solids are particles that are larger than 2 microns, found in the water column and anything smaller than 2 microns (average filter size) is considered as dissolved solid.

Most of the suspended solids are made from inorganic materials, though bacteria and algae can also contribute to the total solids concentration. These solids include anything drifting or floating in the water, from sediment, silt, and sand to plankton and algae. Organic particles from decomposing materials can also contribute to the TSS concentration.

For measuring suspended solids, the water is filtered through a fine filter (Whattmann, Grade 1, $110 \mathrm{~mm} \phi$ ) and the dried and cooled material retained on the filter is weighed. The drying was carried out for one hour in an oven at $105^{\circ} \mathrm{C}$. The filter paper was dried prior to the filtration for 30 minutes in order to make the water content of the filter paper equal to that after drying with filtered out impurities. Hence, the filter paper with impurities dried in the oven is kept in the room temperature for about 30 minutes for cooling and then only its weight is determined
Total suspended solids in $\mathrm{g} / \mathrm{l}=$

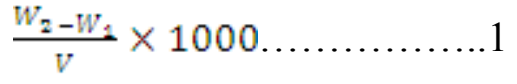

Where,

$\mathrm{W}_{1}=$ Initial weight of filter paper, $\mathrm{g}$

$\mathrm{W}_{2}=$ Weight of filter paper and the dry material retained on the filter, $g$

$\mathrm{V}=$ Volume of water sample, $\mathrm{ml}$

\section{Estimation of filter efficiency of suspended solids}

Filter efficiency refers to the amount of removal of impurities by the filter system. Hence, the filtration efficiency has been worked out based on the removal of the suspended impurities. For this, the concentrations of suspended solids in the water before filtering and after filtering were found by the gravimetric method. Then, efficiency of the filters has been determined by the following equation.

$$
\mathrm{E}=\frac{S_{b}-S_{a}}{S_{b}} \times 100 \ldots \ldots \ldots \ldots . . .2
$$

Where,

$\mathrm{E}=$ Efficiency of the filter, \%

$\mathrm{Sb}=$ Suspended solids before filtering, $\mathrm{mg} / \mathrm{l}$.

$\mathrm{Sa}=$ Suspended solids after filtering, $\mathrm{mg} / \mathrm{l}$.

\section{Discharge rate of different filter systems}

\section{Volumetric measurement}

Discharge rate of the micro mesh filters are very important as the filter system demands high flow rate during different rainfall events, especially during high rainfall intensities. If the filter discharge rate is less, there will be overflow of rooftop collected water from gutters which give rise to loss of water in one account and undesirable situation of falling water from the higher levels to the ground. Hence, discharge rates of every micro mesh 
filter was evaluated. For the discharge measurements, outflow from the filters were collected for a known time and the volume of collected water is measured to get the discharge. The discharge of the various filters has been determined by the following equation.

$\mathrm{D}=\frac{W}{T} \ldots \ldots \ldots \ldots . .3$

Where,

$\mathrm{D}=$ Discharge, $(1 / \mathrm{s})$

$\mathrm{V}=$ Volume, $(\mathrm{l})$

$\mathrm{T}=$ Time, $(\mathrm{s})$

\section{Results and Discussion}

The performance evaluation of automatic cleaning mechanism for roof water harvesting system developed for the study is presented here. Micromesh filters of various mesh sizes were evaluated with regard to the purification of roof water. Various water quality parameters tested were $\mathrm{pH}, \mathrm{EC}, \mathrm{SAL}$, TDS and TSS. Performance evaluation of the automatic flush was mainly done based on TSS gravimetric method.

\section{Performance evaluation of the automatic flush}

Operation and the performance of the automatic flush to remove the filtered out impurities from the mesh filter unit was tested thoroughly. The light based opening of the solenoid valve was taking place once in a day. Duration of the opening of the valve was for 10 seconds. It was found that opening of the solenoid valve for 10 seconds duration was sufficient to remove all the water stagnant in the upward flow filter mechanism. The removal efficiency of the rooftop impurities in the stagnant water was evaluated by quantifying the impurities load before and after the flush out. About 1001 of rooftop water was allowed to pass through the filter unit.

The impurity load in the stagnant water in the filter system was measured by gravimetric method before and after the automatic flush out. It was found that, the impurity load was $37.98 \mathrm{~g}$ before the automatic flush out and after flushing out the remaining impurities load in the system was $3.20 \mathrm{~g}$. The result is presented in figure 3 . Percentage removed of impurities was $92 \%$. Further, the automatic flushing unit was draining the filter unit completely avoiding all possibilities of any anaerobic decomposition. It can be concluded that the automatic flushing unit was a success in improving the performance of the upward flow filter system.

Table.1 Mesh area and slot area of different filter elements

\begin{tabular}{|l|l|l|l|}
\hline Mesh size $(\boldsymbol{\mu})$ & Mesh area $\left(\mathbf{c m}^{2}\right)$ & No. slots & Slot area $\left(\mathbf{c m}^{2}\right)$ \\
\hline 60 & 447.45 & 229 & 44.96 \\
\hline 40 & 447.45 & 124 & 24.35 \\
\hline 25 & 447.45 & 196 & 38.48 \\
\hline 15 & 447.45 & 230 & 45.16 \\
\hline 12 & 447.45 & 230 & 45.16 \\
\hline 7 & 447.45 & 230 & 45.16 \\
\hline 5 & 447.45 & 230 & 45.16 \\
\hline 3 & 447.45 & 230 & 45.16 \\
\hline
\end{tabular}


Fig.1 Upward flow micro mesh filter with automatic flush

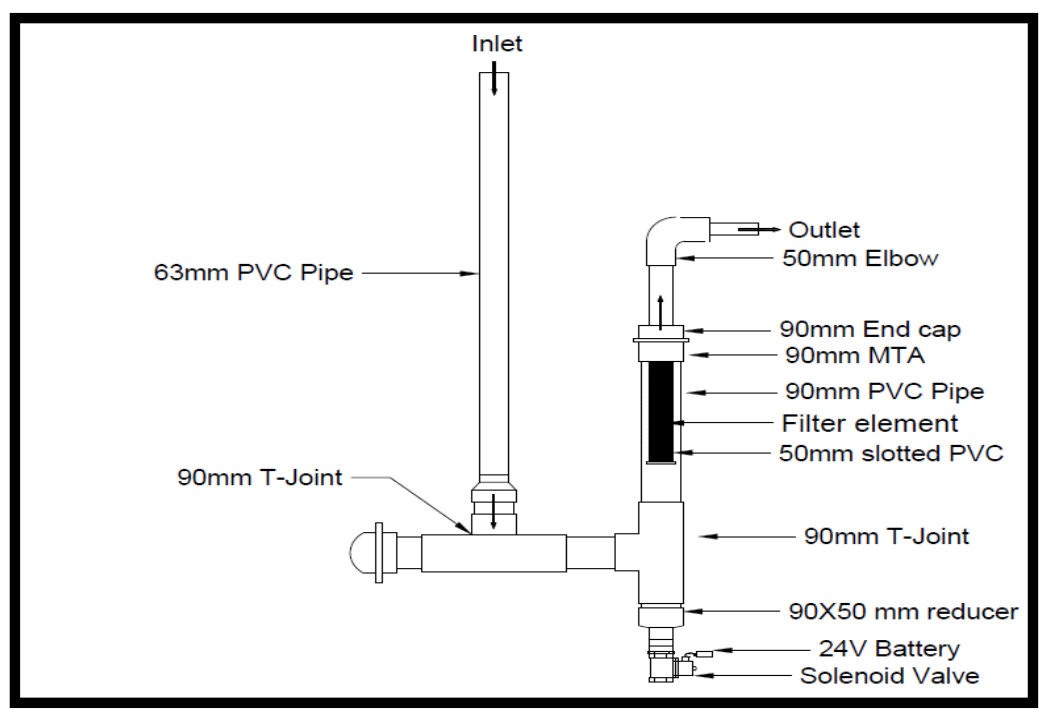

Fig.2 Circuit diagram of automatic flush
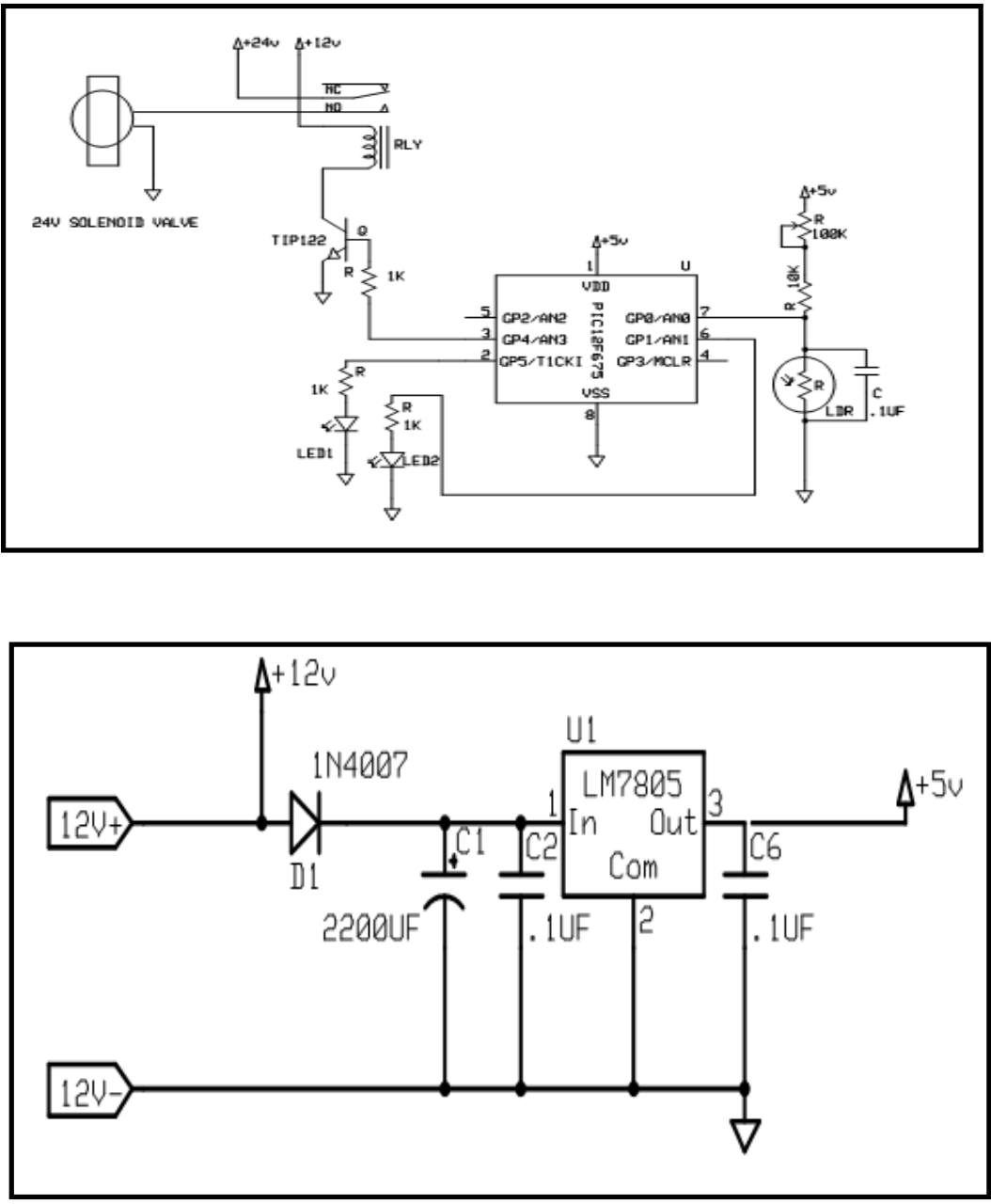
Fig.3 Impurities load in the filter system before and after automatic flush out

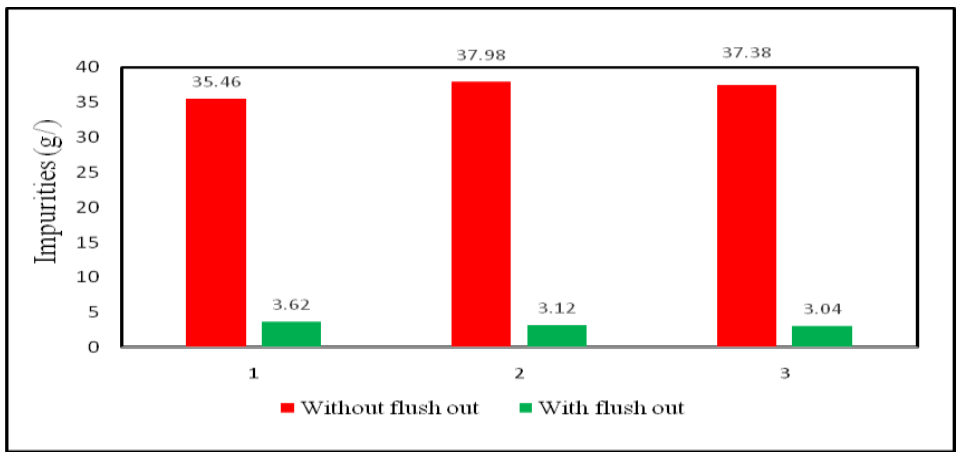

Fig.4 Filtration efficiency of different micro mesh filters

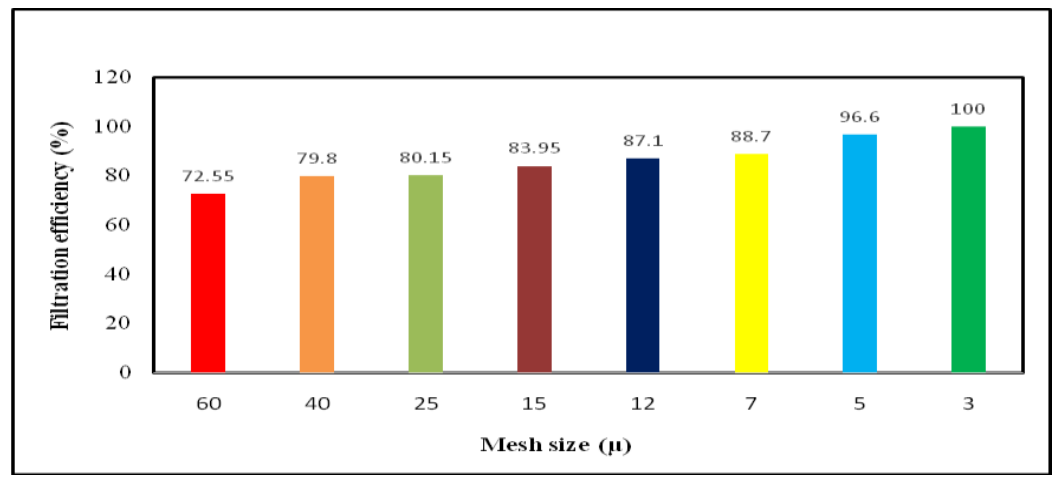

Fig.5 Discharge rate of different filters per unit mesh area

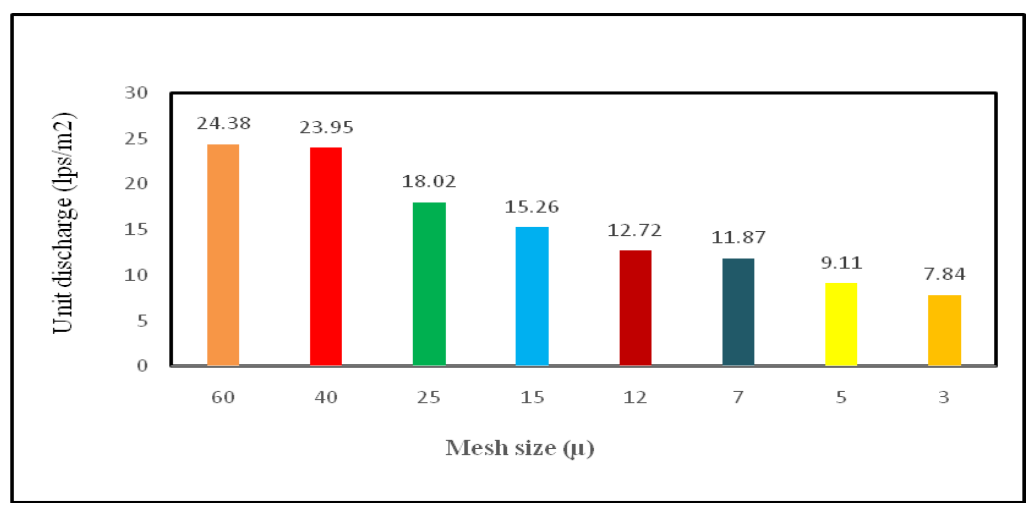

\section{Filtration efficiency of suspended solids}

The main function of the mesh filters are the removal of suspended matter. Along with the removal of suspended impurities it also helps in reducing the presence of other undesirable material and improves the overall quality of portability of roof water. Hence, the filtration efficiency of the mesh filters was evaluated from the point of removal of suspended impurities. The result is presented in figure 4 and it shows very high efficiencies in the case of all the eight filters. As expected, when the mesh size decreases, the efficiency increases and the highest efficiency of $100 \%$ is obtained for 3 micron mesh filter.

\section{Discharge rate of different filter systems}

Discharge rate of the different filters are important in the case of roof water harvesting. As rain last for shorter intervals, the incoming 
roof water to the filter system also will be for short duration but with high discharge. Here, volumetric measurement was adopted in determining the filtration rate. This information will be of great use to others in designing mesh filters to suit to their requirement. The discharge rates of different filters at a hydraulic head of $1.5 \mathrm{~m}$ are presented in figure 5 . Even 3 micron filter has a discharge of $0.37 \mathrm{l} / \mathrm{s}$ under a head of flow of $1.5 \mathrm{~m}$. Filtration rate per unit area of mesh has also been worked out. This discharge rate is sufficient to contain the roof water inflow expected for high rainfall intensities.

In conclusion the automatic flush system with solenoid valve, light sensor and electronic circuit developed for the automatic cleaning of the upward flow mesh system was capable of opening the valve for about 10 seconds once a day. The performance of the filter unit in removing the impurities retained after the rain water filtration showed that automatic flush was removing $92 \%$ of the retained impurities on the inlet side of the micro mesh filter. Also it empties the rainwater retained in the upward flow filter system completely and eliminates the possibility of any anaerobic decomposition. Filtration rate of mesh filters were sufficient for roof water harvesting, even $3 \mu$ mesh gave a filtration rate of $0.37 \mathrm{l} / \mathrm{s}$ at a hydraulic head of $1.5 \mathrm{~m}$. It can be concluded that 3 micron mesh filter with automatic flush can function as a fool proof mechanism for filtering rooftop rain water.

\section{References}

Helmreich, B. and Horn, H. 2008. Opportunities in rainwater harvesting. IWQC, Germany. pp. 118-124.

Kahinda, J.M., Taigbenu, A.E., and Boroto, J.B. 2007. Domestic rainwater harvesting to improve water supply in rural South Africa. J. Phys. Chem. Earth, 32: 10501057.

Kaposztasova, D., Vranayova, Z., Markovic, and Purczb, P. 2014. Rainwater harvesting, risk assessment and utilization in Kosice- city, Slovakia. J. Procedia Eng., 89: 1500 -1506.

Lee, Y., Bak, G., Han, M. 2012. Quality of roof-harvested rainwater- comparison of different roofing materials. Environ. Pollut., 162: 422- 429.

Manoj, P.S. and Mathew, A.C. 2008. Rejuvenation of water bodies by adopting rainwater harvesting and groundwater recharging practices in catchment area- a case study. ICAR CPCRI, Pp.1-11.

Mendez. C.B., Brandon, K., and Brigit R.A. 2011. The effect of roofing material on the quality of harvested rainwater. $J$. Water Res., 45: 2049 -2059.

Rahmat, S., Zarina M., Sabariah, M. 2008. Treatment of rainwater quality using sand filter. Int. Conf. on Environ.

Rajan, S. 2001. Making water everybody's business practices and policy of water harvesting, pp. 122-124.

Reena, K. and Sherring, A. 2012. Planning and cost estimation of roof rainwater harvesting structure. Int. J. Agric. Environ. Biotechnol., 5(3): 225-232.

\section{How to cite this article:}

Lakshminarayana, S.V. and Sathian, K.K. 2017. Development of an Automatic Cleaning Mechanism for the Mesh Filter of Roof Water Harvesting. Int.J.Curr.Microbiol.App.Sci. 6(4): 530536. doi: https://doi.org/10.20546/ijcmas.2017.604.064 